5 The Applicability of Self-Regulation Theories in Sport: Goal Adjustment Capacities, Stress

10 Nicholls, A. R., Levy, A. R., Carson, F., Thompson, M. A., \& Perry, J. L. (in press). The 11 applicability of self-regulation theories in sport: Goal adjustment capacities, stress appraisals, 12 coping, and well-being among athletes. Psychology of Sport and Exercise. 
2 Objectives: We examined a model, informed by self-regulation theories, which included goal

3 adjustment capacities, appraisals of challenge and threat, coping, and well-being.

4 Design: Prospective.

5 Methods: Two hundred and twelve athletes from the United Kingdom $(n=147)$ or Australia

$6 \quad(n=65)$, who played team $(n=135)$ or individual sports $(n=77)$, and competed at

7 international $(n=7)$, national $(n=11)$, county $(n=67)$, club $(n=84)$, or beginner $(n=43)$

8 levels participated in this study. Participants completed measures of goal adjustment

9 capacities and stress appraisals two days before competing. Athletes also completed questions on coping and well-being within three hours of their competition ending.

11 Results: The way an athlete responds to an unattainable goal is associated with his or her

12 well-being in the period leading up to and including the competition. Goal reengagement

13 positively predicted well-being, whereas goal disengagement negatively predicted well-being.

14 Further, goal reengagement was positively associated with challenge appraisals, which in turn

15 was linked to task-oriented coping, and task-oriented coping positively associated with well-

16 being.

17 Conclusion: When highly-valued goals become unattainable, consultants could encourage

18 athletes to seek out alternative approaches to achieve the same goal or help them develop a

19 completely new goal.

20 Keywords: Challenge; Disengagement; Reengagement; Threat 
The Applicability of Self-Regulation Theories in Sport: Goal Adjustment Capacities, Stress Appraisals, Coping, and Well-Being among Athletes

Goal setting is widely used in sport (i.e., Healy, Ntoumanis, Veldhuijzen van Zanten, \& Paine, 2014) and can be very helpful in aiding performance (Staufenbiel, Lobinger, \& Strauss, 2015). The effectiveness of goal setting interventions for goals that become increasingly difficult or unattainable is unknown. On the whole, striving to achieve one's goal is portrayed positively within society, but giving up is seen as a weakness (Ntoumanis, Healy, Sedikides, Smith, \& Duda, 2014a). Understanding more about athletes’ responses to unattainable goals may be useful in maximizing well-being during periods of difficulty, by helping athletes deploy the most effective strategies. Indeed, the realization that one is unable to achieve his or her goal is likely to be very stressful, as stress is caused when goals become unattainable (Lazarus, 1999). Further, Smith, Ntoumanis, Duda, and Vansteenkiste (2011) linked goal status to coping, via appraisals among athletes, whilst other researchers linked goal adjustment capacities, coping, and indicators of well-being among caregivers (Wrosch, Amir, \& Miller, 2011). In particular, Wrosch et al. (2011) reported positive associations between both goal disengagement and goal reengagement with well-being. It is noteworthy that Wrosch et al. did not explore appraisal, given recent findings linked goal adjustment capacities to appraisals (Smith et al., 2011). As such, we assessed how goal adjustment capacities and stress appraisals predicted well-being in the lead up to and during a competition. We also assessed how athletes coped during competition within a single model to satisfy calls for more research to identify the psychological mechanisms that link goal adjustment capacities with indicators of well-being (Wrosch et al).

Self-regulation theorists (i.e., Carver \& Scheier, 1981, 1998; Emmons, 1986;

Heckhausen, Wrosch, \& Schulz, 2010) argue that goals structure a person’s life and facilitate adaptive behaviors, which contribute to a person's well-being or positive mental health. 
1 Personal goals for an athlete's next competition such as winning an event, achieving a

2 personal best, or beating a specific opponent, may, at some point, become unattainable. This can happen for a number of reasons, such as injury, biological capabilities, or time constraints (Ntoumanis et al., 2014a). In order to circumvent the negative consequences of failing to achieve one’s goal, individuals can deploy self-regulation strategies, such as disengaging from their goal and reengaging in alternative goals (Wrosch, Scheier, Carver, \& Schulz, 2003). Goal disengagement refers to withdrawing effort and commitment from achieving an unattainable goal, whereas goal reengagement involves identifying alternative approaches to achieve the same goal, identifying different goals that relate to the overall goal, or developing a completely new goal (Carver \& Scheier, 2005). The key feature of goal reengagement is that the individual is committed to his or her new goal pursuit (Wrosch et al., 2011). Coping refers to all cognitive and behavioral efforts that are used to help an individual manage external or internal demands that are appraised as taxing a person’s resources (Lazarus \& Folkman, 1984). There are many different ways of classifying coping, but a popular approach involves grouping coping strategies task-, distraction-, and disengagement-oriented dimensions (Gaudreau \& Blondin, 2004). Task-oriented coping includes attempts to master stressful situations, whereas distraction-oriented coping relates to focusing on cues that are irrelevant to sport, and disengagement-oriented coping involves athletes ceasing their efforts to strive for personal goals. It is worth noting that coping is associated with sporting performance and goal attainment. With a sample of elite fencers, Doron and Gaudreau (2014) reported that task-oriented coping predicted winning streaks, whereas Schellenberg, Gaudreau, and Crocker (2013) reported a positive association between task-oriented coping and goal attainment, but a negative association between disengagementoriented coping and goal attainment. At present, there does not appear to be an association between distraction-oriented coping and actual performance (Gaudreau, Nicholls, \& Levy, 
1 2010). In addition to the association between coping and performance, health psychology

2 researchers reported a link between coping and well-being (Pérez-García, Oliván, \& Bover, 2014).

Well-being includes affective and psychological functioning, which relates to two specific perspectives, the hedonic and the eudaimonic perspectives. The hedonic perspective views psychological well-being as subjective experiences of happiness and defines wellbeing in terms of pleasure attainment and pain avoidance. Conversely, the eudiamonic perspective of well-being defines well-being in regards to the degree to which a person can function fully (Ryan \& Deci, 2001). These two conceptualizations of well-being resulted in different strands of research and questionnaires that measured well-being from one perspective, but not the other. However, examining well-being using a questionnaire, which only captures either the hedonic or eudiamonic perspective, means that the entire well-being construct is not captured. In order assess all components of well-being, without placing a substantial time burden on participants, researchers such as Tennant et al. (2007) suggested scholars should conceptualize and develop well-being scales that incorporate both the hedonic and eudiamonic perspective. Combining the hedonic and eudaimonic perspectives provides a broad conceptualization of well-being, which is viewed as another term for positive mental health, with positive mental health and well-being often used interchangeably (Tennant et al.). As such, well-being or positive mental health are associated with people fulfilling their abilities, coping with stresses in life, and working productively or fruitfully (World Health Organization, 2004). Despite the association between coping and well-being, studies exploring these constructs among athletes are scant. One exception is the study by Smith et al. (2011), who did not report any significant associations between emotional wellbeing and coping. A possible explanation for this finding may the scale employed by Smith and colleagues. These authors measured emotional well-being using 10 items from the 
1 Positive and Negative Affect Schedule (Watson, Tellegen, \& Clark, 1988). Unfortunately,

2 this scale only captures the affective-emotional elements of well-being. It does not measure cognitive-evaluative or psychological functioning and thus fails to capture a wide conception of well-being (Tennant et al., 2007). In health domains, researchers reported a direct association between well-being and coping. With a sample of heart-failure patients, PérezGarcía et al. (2014) reported a positive association between task-focused strategies and wellbeing, but a negative association between maladaptive coping (i.e., behavioral disengagement and self-blame) and well-being. There are a number of positive outcomes of well-being, so identifying mechanisms that may enhance well-being is important. Goal adjustment capacities may be one antecedent of psychological well-being.

In non-sport settings, researchers revealed the importance of goal adjustment capacities, in regards to well-being. Wrosch et al. (2003), for example, found goal disengagement predicted enhanced psychological well-being. Persisting in goal-directed behaviours for an unattainable goal may result in psychological distress (Carver \& Scheier, 1990). Disengaging from one’s goals or withdrawing effort and commitment from unattainable goals (i.e., attempting to be fit for a particular competition when there is not enough time for the injured body part to heal) is an adaptive behaviour, because it prevents the individual experiencing an accumulation of failure experiences (Nesse, 2000). Indeed, disengaging from one's attempts to achieve a goal is associated with fewer depressive symptoms or negative affect (Wrosch et al., 2003). Conversely, goal reengagement strategies (e.g., identifying a new date to return to completion after an injury or to return to one's sport stronger) are associated with a greater purpose in life and positively toned emotions (e.g., happiness, excitement, or joy). This is due to the awareness of future opportunities for success in achieving one’s goals (Wrosch \& Miller, 2009; Wrosch, Miller, Scheier, \& Brun de Pontet, 2007). It is the reduction in negative affect, combined with feelings 
1 purposefulness and positive emotions as a consequence of goal adjustment strategies, which

2 are thought to be the mechanisms by which psychological well-being is enhanced (Wrosch et al., 2007). Although Wrosch et al. suggested that goal reengagement strategies are the main source of enhanced psychological well-being, rather than goal disengagement.

Despite Wrosch et al. (2003) reporting that goal disengagement predicted enhanced psychological well-being, their sample did not contain athletes. Existing theory and empirical evidence indicates that goal disengagement might not be associated with such positive outcomes within sporting domains. A theoretical framework that predicts a negative response to goal disengagement is the biopsychosocial model (BPSM) of challenge and threat (Blascovich, 2008). According to this model, threat occurs when personal resources are insufficient to meet the demands of a situation, whereas challenge ensues when an individual perceives his or her resources meet the demands of a situation. Thus, when athletes withdraw effort and commitment (e.g., no longer trying to beat a particular opponent or win a race), they are accepting that their resources are insignificant to meet the necessary demands. They may then experience threat after disengaging from a goal. Alternatively, reengaging with an existing goal, by developing a different approach or identifying a completely new goal, can empower a person's belief to be successful. This is because identifying a new goal or alternative strategy often involves the individual re-appraising a situation differently, which can result in a sense of empowerment (Folkman \& Moskowitz, 2000). Empowerment and feelings of enhanced competence equates to athletes believing they can meet the demands of the situation, and a challenge appraisal is likely to occur under such circumstances (Blascovich, 2008). Indeed, the BPSM (Blascovich) provides a theoretical link between resource evaluations to meet the demands of a situation and challenge or threat states, which is supported by empirical evidence (Tomaka, Blascovich, Kibler, \& Ernst, 1997). Further, the way an athlete appraises a situation (i.e., challenge vs. threat) influences coping (Lazarus \& 
1 Folkman, 1984). This is supported in recent research, whereby appraisals of challenges and

2 threat were significantly associated with task-oriented coping, whereas threat appraisals were

3 linked to distraction-, and disengagement-oriented coping responses among athletes

4 (Nicholls, Perry, \& Calmeiro, 2014).

\section{Summary and Hypotheses}

Firstly, we tested whether goal adjustment capacities, in relation to important goals in the athletes' next competition, predicted well-being in the lead up to, and during a sports competition, and then developed the hypothesized mediator model (see Figure 1) to explain the process via appraisals and coping. We predicted that goal adjustment capacities would be associated with well-being, based on previous research in non-sport domains (Wrosch et al., 2003, 2009), which linked both types of goal adjustment capacities to well-being. In accordance with findings from the health psychology literature, we predicted a positive relationship between goal reengagement strategies and well-being in the two days leading up to, and during a sports competition. However, unlike the findings of Wrosch and colleagues, we predicted a negative relationship between goal disengagement and well-being. Although disengaging from one’s goals may be effective in promoting well-being outside of sporting contexts, disengagement is associated with negative outcomes in sport such as burnout (Schellenberg et al., 2013). Burnout is considered as marker of psychological ill-being (DeFreese \& Smith, 2015). As such, we believed this goal adjustment capacity would predict poorer well-being scores in the two days leading up to and during the competition.

We also predicted positive paths between goal reengagement and challenge, along with goal disengagement and threat, but negative paths from goal reengagement to threat and goal disengagement to challenge. As goal reengagement is associated with people being aware of future opportunities for success in achieving one’s goals (Wrosch \& Miller, 2009; Wrosch et al., 2007), it is likely this would generate a challenge state given the belief in one's 
1 ability to achieve a goal is an antecedent of challenge states (Blascovich, 2008;Tomaka et al.,

2 1997). We predicted a negative path from goal disengagement to threat, because scholars reported an association between disengagement strategies and threat appraisals (Nicholls et al., 2014). We also hypothesized a positive path from challenge, but a negative path from threat to well-being. All of these predictions were based on the notion that a challenge state occurs when people perceive their resources are sufficient to cope, whereas threat ensues when resources are insufficient and the emotional responses associated with each appraisal (Blascovich). A key component of well-being relates to emotional well-being and functioning. Pleasant emotions and superior functioning are associated with challenge states, whereas unpleasant emotions and impaired functioning are a consequence of threat states (Blascovich). Further, empirical evidence also underpins these hypotheses. Schmidt and Muldoon (2015) reported an association between enhanced threat levels and poorer wellbeing. We also predicted a positive path from challenge to task-oriented coping, but negative paths from challenge to distraction- and disengagement-oriented coping. Positive paths from threat to disengagement- and distraction-oriented coping, along with a negative path from threat to task-oriented coping were predicted. The directions of these paths are based upon previous research (i.e., Nicholls et al., 2014; Ntoumanis, Healy, Sedikides, Duda, Stewart, Smith, \& Bond, 2014b). Finally, we predicted a positive path from task-oriented coping to well-being, but negative paths from distraction- and disengagement-oriented coping to psychological well-being, based upon the finding of Pérez-García et al. (2014).

\section{Method}

\section{Participants}

Two-hundred and twelve athletes (male $n=107$, female $n=105$ ), aged between 18 and 25 years of age $(M$ age $=18.96, S D=5.74)$, with a mean playing experience of 5.76 years $(S D=4.38)$, from the United Kingdom $(n=147)$ or Australia $(n=65)$, participated in 
1 the study. Participants played team sports such soccer, rugby union, or rugby league $(n=$

2 135) or individual sports such as tennis, golf, martial arts $(n=77)$. Our sample contained 114

3 Caucasian, 40 African-Caribbean, 26 Asian, 27 Chinese, and five athletes from other ethnic

4 groups. The athletes in our sample competed at international $(n=7)$, national $(n=11)$, county

5 ( $n=67)$, club $(n=84)$, and beginner $(n=43)$ levels, who played their sport professionally $(n$

$6=11)$, semi-professionally $(n=18)$, or as an amateur $(n=183)$.

\section{Measures}

Goal Adjustment Capacities. The Goal Disengagement and Goal Reengagement Scale (GDGRS; Wrosch et al. 2003) assessed the extent to which participants could reduce effort and commitment to unattainable goals, along with pursuing alternative goals. The GDGRS (Wrosch et al.) contains 10 items that are answered on a 5-point Likert-type scale, anchored at $1=$ strongly disagree and $5=$ strongly agree. Participants responded to the stem "If it becomes likely that I am not going to succeed in achieving an important goal or goals in my next competition, in two days time.” Four items of the GDGRS (i.e., “It's easy for me to reduce my effort toward the goal”) measured goal disengagement and six items (i.e., "I think about other new goals to pursue”) measured goal reengagement. With a sample of 115 participants, Wrosch et al. reported a Cronbach’s alpha of .84 for goal disengagement and .86 for goal engagement among 115 undergraduate students.

Challenge and Threat Appraisals. Participants completed challenge and threat questions from the Stress Appraisal Measure (SAM; Peacock \& Wong, 1990) and responded to the stem "This questionnaire is concerned with your thoughts about your next competition in two days time. Please rate the degree to which the following statements apply to you.” There were six challenge questions (i.e., "I am excited about playing in my next competition” and "I am keen to play my next competition" and six threat questions (i.e., "I think the outcome of my next competition will be negative” and "my next competition could have 
1 negative consequences for me.”) Questions were answered on a Likert-type scale, ranging

2 from $1=$ not at all to $5=$ extremely. Internal consistencies ranged from .65 to .90 with a sample of 100 participants. Peacock and Wong report three Cronbach alpha scores for threat

4 (i.e., .65, .75, and .73) among their samples of undergraduate students.

Coping. The Coping Inventory for Competitive Sport (CICS; Gaudreau \& Blondin, 2002) measured how the athletes coped during competitive sport. The CICS is a 39-item questionnaire, which assesses three second-order dimensions, from 10 coping subscales. These are task-oriented coping (i.e., thought control, mental imagery, relaxation, effort expenditure, logical analysis, and seeking support), distraction-oriented coping (i.e., distancing and mental distraction), and disengagement-oriented coping (i.e., disengagement/resignation and venting of unpleasant emotions). Participants responded to the stem "Each question represents things that athletes can do or think during sport. For each question your must indicate the extent to which it corresponds to what you did during your sport today. We are interested in what you actually did or thought during your sport.” "I visualized that I was in total control of the situation" and "I lost all hope of attaining my goal” are examples of questions within the CICS (Gaudreau \& Blondin, 2002). Participants answered these questions on a 5-point Likert-type scale, anchored at $1=$ not at all and $5=$ very strongly. Gaudreau and Blondin (2002) reported Cronbach alpha coefficients for individual coping strategies ranging from .67 to .87 among their sample of 314 athletes.

Well-being. The Short Warwick Edinburgh Mental Well-Being Scale (SWEMWBS; Tennant et al., 2007) examined well-being among the participants. Participants responded to the stem "Below are some statements about feelings and thoughts. Please circle the number that best describes your experience of each over the last couple of days.” The SWEMWBS (Tennant et al.) contains seven questions (i.e., “I’ve been able to make up my own mind about things” and “I’ve been feeling optimistic about the future”) that are answered on a 5- 
1 point Likert-type scale ranging from $1=$ none of the time to $5=$ all of the time. Tennant et al.

2 reported Cronbach's alphas of .89 for their student sample of 354 students and .91 for 2075

3 participants who were classified as a general population sample.

4 Procedure

Following ethical approval from a University Ethics Committee, letters detailing the nature of the study were sent to sports teams. Those athletes interested in participating in the study signed a consent form. The participants filled out the GDGRS (Wrosch et al., 2003) and then the challenge and threat items of the SAM (Peacock \& Wong, 1990) two days before, and in relation to the athletes' next sporting competition (T1). Participants then completed the CICS (Gaudreau \& Blondin, 2002) in relation to their coping during the competition, followed by the SWEMWBS (Tennant et al., 2007), in the presence of a research assistant, to assess well-being throughout the duration of the study, which included the two days leading up to the competition and the competition itself. The CICS and the SWEMWBS were completed within three hours of their competition finishing (T2).

\section{Data Analysis}

We used descriptive statistics to examine missing data, outliers, and univariate normality. Omega point estimates and bootstrapped confidence intervals assessed internal consistency (i.e., Dunn, Baguley, \& Brunsden, 2013). Owing to our sample size, a full structural equation model, including a measurement model, was not possible. Therefore, we explored the factor structure of each measure by employing exploratory structural equation modelling (ESEM; Asparouhov \& Muthén, 2009), with a subjective view of fit indices (Marsh, Hau, \& Wen, 2004; Perry, Nicholls, Clough, \& Crust, 2015).

For the main analysis, we tested a structural equation model, employing the robust maximum likelihood (MLR) estimator to guard against departure from multivariate normality. Standardized parameter estimates, bootstrapped to provide 95\% confidence 
1 intervals, examined model fit. Specifically, the comparative fit index (CFI) and Tucker-Lewis

2 Index (TLI) were examined as normed and non-normed indices. The standardized root-meansquare residual (SRMR) and the root mean square error approximation (RMSEA) presented absolute fit indices. We tested our hypotheses in two stages. First, we tested a model whereby well-being was predicted directly by goal disengagement and goal reengagement. Next, we examined the hypothesized mediator model, where the direct path between goal adjustment and well-being was mediated by stress appraisal and coping.

\section{Results}

Preliminary analyses found no missing data or issues with outliers. Table 1 contains descriptive statistics and omega point estimates. There were no issues with univariate skewness $(<2)$ or kurtosis $(<2)$. We calculated Omega point estimates and confidence intervals using the MBESS package (Kelley \& Lai, 2012), in R (R Development Core Team, 2012), with 1,000 bootstrap samples. All demonstrated acceptable internal consistency. Table 2 includes Pearson's bivariate correlations between all variables.

It was not possible to conduct a full structural equation model including requisite measurement models, as the ratio of participants to free parameters was insufficient (Bentler \& Chou, 1987). To explore factor structure was appropriate, we conducted ESEM on each scale before proceeding to the main analysis. We scrutinized model fit and standardized parameter estimates to ensure theoretically sensible loadings and that cross-loadings were not substantive. The GDGRS presented a reasonable model fit; $\chi^{2}(26)=86.42, p<.001$, CFI $=$ $.913, \mathrm{TLI}=.836, \mathrm{SRMR}=.051, \mathrm{RMSEA}=.111(90 \% \mathrm{CI}=.086, .137)$. All items loaded significantly onto their intended factor with two significant cross-loadings. Specifically, two disengagement items loaded onto the reengagement factor, though these were lower than their intended factor loading. Consequently, the GDGRS (Wrosch et al., 2003) demonstrated appropriate measurement of goal adjustment capacities in the sample. The SAM (Peacock \& 
1 Wong, 1990) presented good ESEM model fit; $\chi^{2}(13)=26.23, p=.001$, CFI $=.971$, TLI $=$ $.932, \mathrm{SRMR}=.030, \mathrm{RMSEA}=.075(90 \% \mathrm{CI}=.035, .114)$. All items loaded significantly onto their intended factors and there were no substantive cross-loadings.

5 (Gaudreau \& Blondin, 2002). Consequently, we tested an ESEM measurement model in

6 which three latent variables, task- distraction-, and disengagement-oriented coping were

7 indicated by the 10 subscales from the CICS. This presented good model fit; $\chi^{2}(18)=24.65, p$

$8=.103, \mathrm{CFI}=.973, \mathrm{TLI}=.930, \mathrm{SRMR}=.031, \mathrm{RMSEA}=.065(90 \% \mathrm{CI}=.000, .118)$. The

final factor structure examined was the unidimensional, 7-item WEMWBS. Model fit was good; $\chi^{2}(14)=19.16, p=.118, \mathrm{CFI}=.983, \mathrm{TLI}=.972, \mathrm{SRMR}=.035, \mathrm{RMSEA}=.045(90 \%$ $\mathrm{CI}=.000, .086)$ and all items loaded substantively onto the single factor. Overall, the preliminary analyses supported the use of published measurement models in the current sample without the need for modification.

\section{Structural Equation Modeling}

We tested the hypothesized model using SEM in Mplus 7 (Muthén \& Muthén, 2012).

Due to the sample size, each latent variable was indicated by one observed variable, which represented the mean score of all items representing the factor, as performed by Ntoumanis et al. (2014). Before testing the hypothesized model, we examined a model whereby well-being in the lead up to, and during the competition was predicted by goal disengagement and goal reengagement. This model fitted the data reasonably well; $\chi^{2}(1)=1.72, p=.189$, CFI $=.969$, TLI $=.907$, SRMR $=.051$, RMSEA $=.059(90 \%$ CI $=.000, .104)$. More meaningfully, wellbeing was significantly and positively predicted by goal reengagement $(\beta=.33, p<.001)$ and negatively predicted by goal disengagement $(\beta=-.26, p<.001)$. We then tested the hypothesized model to examine the extent to which the effects between goal adjustment capacities and well-being were mediated by stress appraisal and coping. Model fit was 
1 reasonable; $\chi^{2}(12)=22.43, p=.021, \mathrm{CFI}=.967, \mathrm{TLI}=.916, \mathrm{SRMR}=.054, \mathrm{RMSEA}=.070$

2 (90\% CI $=.026, .112)$, but indicated some misspecification. Inspection of the modification

3 indices signaled that the addition of a direct path from threat to well-being would

4 significantly improve model fit. This conceptually viable path (i.e., Blascovich, 2008, Schmid

5 \& Muldoon, 2015) created the final model shown in Figure 2. Model fit improved, including

6 achieving a non-significant chi-square statistic; $\chi^{2}(11)=18.01, p=.081$, CFI $=.980$, TLI $=$

$7.949, \mathrm{SRMR}=.041, \mathrm{RMSEA}=.055(90 \% \mathrm{CI}=.000, .099)$. All paths in the model were

8 statistically significant with the exception of threat appraisal to disengagement-oriented

9 coping. With the exception of the path between distraction-oriented coping and

psychological well-being $(\beta=.27, p<.001)$, the direction of the other parameter estimates

were as expected. Overall, the direct effects indicated that goal disengagement predicted threat stress appraisal, which predicted lower psychological well-being. Conversely, goal reengagement predicted challenge stress appraisal, which predicted task-oriented coping, which predicted higher psychological well-being. The negative paths opposing these positive ones were also significant.

To determine indirect effects from goal adjustment capacities to psychological wellbeing, 95\% confidence intervals were obtained from 5000 bootstrapped samples. Significant indirect effects were evident from goal disengagement to well-being via challenge and taskoriented coping $(\beta=-.08, p<.001,95 \% \mathrm{CI}=-.13,-.02)$, and challenge and distractionoriented coping $(\beta=.05, p<.01,95 \% \mathrm{CI}=.01, .10)$. Total indirect effects from goal disengagement to psychological well-being were negative $(\beta=-.16, p<.05,95 \% \mathrm{CI}=-.32$, .01). Significant indirect effects from goal reengagement to well-being were observed via challenge and task-oriented coping $(\beta=.09, p<.001,95 \% \mathrm{CI}=.03, .15)$, challenge and distraction-oriented coping $(\beta=-.06, p<.001,95 \% \mathrm{CI}=-.11,-.01)$, and threat $(\beta=.11, p<$ 
$1.05,95 \% \mathrm{CI}=.00, .23)$. Total indirect effects from goal reengagement to psychological well-

2 being were positive $(\beta=.18, p<.001,95 \% \mathrm{CI}=.04, .32)$.

\section{Discussion}

Informed by self-regulation theories (i.e., Carver \& Scheier, 1981, 1998; Emmons, 1986; Heckhausen et al., 2010), we tested a model that included goal adjustment capacities, appraisals, coping, and well-being. As such, the objective of this study was to shed light on the relationship between goal adjustment capacities and well-being among athletes, and examine the psychological constructs that may link these two variables (i.e., appraisal and coping). Overall, we found support for our model and many of the hypothesized paths were significant, inferring the way in which an athlete responds to an unattainable goal is associated with his or her well-being. In particular, well-being during the two days leading up to, and including the competition was negatively predicted by goal disengagement, but positively predicted by goal reengagement. This is in partial agreement with research from the health psychology literature, where both goal reengagement and disengagement positively predicted well-being (Wrosch et al., 2003, 2011). We offer two explanations for our contrasting findings. These differences may be due to the different contexts in which the data was collected and therefore the nature of the stress experienced. The participants in the Wrosch et al. (2011) study faced a chronic stressor (i.e., being a caregiver for a family member with a mental illness), whereas we examined an acute stressor (i.e., the stress encountered during sport). As such, goal adjustment capacity strategies that involve disengagement may be effective for chronic stress. Alternatively, goal disengagement may have been negatively linked to poorer well-being, because the athletes performed poorer, and thus reported poorer well-being scores. We did not assess sporting performance, but previous scholarly activity found a negative association between disengagement-oriented coping and goal attainment (Schellenberg et al., 2013). Future research is required to explore factors that 
1 may shape the relationship between goal disengagement and well-being to inform both theory

2 and applied practice. This study therefore highlights the nuances of conducting sport specific research and illustrates within the context of sport, findings may be different from other populations.

The paths between goal adjustment capacities and stress appraisals supported our hypotheses, with positive paths from goal disengagement to threat and from goal reengagement to challenge. Further, the paths from goal disengagement to challenge and goal reengagement to threat were negative. Folkman and Moskowitz (2000) suggested that developing a new goal may involve an element of re-appraisal, which allows the person to identify new solutions to a problem (i.e., no longer being able to achieve one’s goal). Some goals become unattainable due to personal reasons such as an athlete not dedicating enough time to their conditioning program, technical skills, or tactics (Ntoumanis et al., 2014a). These reasons could be resolved by the athlete re-appraising the situation and setting a goal to work on these individual aspects. Under these circumstances, athletes may then view their situation as challenging, because of their new strategy (Blascovich, 2008). Alternatively, if goal failure is down to factors that go beyond the control of the athlete (i.e., selectors not picking an athlete, injury, or illness) then the relationship between goal reengagement and challenge appraisals may be different, because no amount of reappraisal strategies can solve the problem. In this study, we did not examine the controllability of goal failure. Exploring control in relation to goal attainment may be an interesting avenue for future research, as it may influence the effectiveness of goal reengagement strategies. An alternative explanation for the relationship between goal adjustment capacities and appraisals may be due the athletes' emotional responses. We did not explore emotions within our model, and thus the emotional responses to different goal adjustment capacities. It is plausible, however, that reengaging in a new goal would result in a pleasant emotion such as hope, relief, or happiness 
1 because of the athlete's new plan, whereas disengaging in a goal would be associated with an unpleasant emotion such dejection, anger, or anxiety, due to feelings of hopelessness.

Previous scholarly activity linked pleasant emotions with challenge appraisals and unpleasant emotions with threat appraisals (Nicholls et al., 2014; Nicholls, Polman, \& Levy 2012).

5 Future research could explore emotional responses in relation to goal adjustment capacities in order to shed more light on this relationship. Further, in the present model, goal adjustment capacities preceded appraisals of challenge and threat. Given that these constructs were assessed at the same point in time, it is plausible that appraisals of challenge or threat may influence the type of goal adjustment capacity deployed. In order to assess causality, and thus whether goal adjustment capacities cause different appraisals or whether appraisals cause different goal adjustment capacities, experimental research is required. The paths from stress appraisals of challenge and threat to coping provide some support for our hypotheses and existing literature (e.g., Nicholls et al., 2014; Ntoumanis et al. 2014b). We found a positive path from challenge to task-oriented coping, but a negative path from challenge to disengagement-oriented coping. Further, path from threat to distractionoriented coping was positive and there was a negative path from threat to task-oriented coping. These results were obtained despite our measurement period not being as close to competition as other studies (i.e., Nicholls et al. 2012). For example, Nicholls et al. (2012) examined appraisals within one hour of a competition starting and coping within an hour of the competition finishing, whereas Nicholls et al. (2014) assessed appraisals and coping together, before a competition started. Ntoumanis et al. examined these constructs after participants completed a laboratory task. In the present study, we assessed appraisals two days before a competition and coping within three hours of the competition ending. This finding indicates the strength of appraisals in predicting coping several days later and provides support for Lazarus’ (1999) assertion that appraisal is the most important construct 
1 within his Cognitive-Motivational-Relational theory of emotions. Our finding also suggests

2 that practitioners may be able to manipulate coping by providing appraisal training in the

3 build up to competitions, and thus enhance performance if athletes use task-oriented

4 strategies when competing (e.g., Doron \& Gaudreau, 2014; Gaudreau et al., 2010;

$5 \quad$ Schellenberg et al., 2013).

6 Appraisal training may also influence well-being. We found a negative and significant

7 path between threat and well-being. It is unsurprising that this path was negative.

8 Conceptually, threat states are associated with athletes being concerned about future losses

9 due to deficiencies in coping (Lazarus, 1999), whereas well-being is related to people being able to cope with stresses (World Health Organization, 2004). As such, decreasing threat levels may be more effective in improving well-being than increasing challenge states. Research is required to assess the impact of appraisal training interventions on well-being. The three paths between coping and well-being were significant, although not all in the anticipated direction. The positive path between task-oriented and well-being and the negative path between disengagement-oriented are in agreement with Pérez-García et al.’s (2014) findings among patients with heart-failure and our hypotheses. As such, the PérezGarcía results transfer to a sport setting and appear that they are not context specific. The notion that coping and well-being are associated provides conceptual support for Lazarus (1999) who stated that when a person copes well, stress will be low, and therefore well-being will be enhanced. The path between distraction-oriented coping and well-being was somewhat unexpected in the present sample. We predicted a negative path between the constructs, but the path was positive. Our prediction was based on previous studies that identified a negative path between distraction-oriented coping and coping effectiveness (i.e., Nicholls, Levy, \& Perry, 2015; Nicholls, Perry, Jones, Morley, \& Carson, 2013). As distraction-oriented coping was deemed to be an ineffective coping in the aforementioned 
1 studies, we believed it would be associated with higher stress levels and thus poorer well-

2 being. We offer two explanations for the present findings. The use of distraction-oriented

3 coping involves athletes thinking about things other than the competition, to distract

4 themselves from the stressful competition. Similar to the conceived benefits of goal

5 disengagement, this form of coping may reduce distress and by taking the athlete's mind off

6 what is causing him or her stress, and thus enhance well-being (Wrosch et al., 2007).

7 Alternatively, the positive relationship between distraction-oriented coping and well-being

8 might be due to some athletes using high levels of distraction-oriented coping in combination

9 with high-levels of task-oriented coping. Shimazu and Schaufeli (2007) reported that workers

10 using high levels of task and distraction based coping strategies experienced lower stress levels, in comparison to high task and low distraction. We did not specifically examine the interplay between these coping strategies, and examining clusters in coping patterns is not a new line of research (i.e., Gaudreau \& Blondin, 2004), but has the potential to reveal the antecedents of well-being. Generally, researchers tend to examine the associations between certain strategies or coping dimensions and other constructs such as performance (i.e., Doron \& Gaudreau, 2014; Gaudreau et al., 2010), goal attainment (Schellenberg et al., 2013) or coping effectiveness (e.g., Nicholls et al., 2013), without assessing combinations of different coping strategies in relation to different outcomes. Adopting this approach may help scholars develop more effective coping interventions by identifying the most efficient ways to cope. At the present time, there appears to be no association between performance and distractionoriented coping (e.g., Gaudreau et al., 2010), so although encouraging athletes to use more distraction coping strategies may not affect performance, it may enhance well-being. being over the course of the assessment period (i.e., two days), which is in accordance with previous research (Wrosch et al., 2011). This meant we did not measure how the participants 
1 were feeling throughout specific phases (i.e., immediately pre- or post-competition). Future

2 research could explore temporal indicators of well-being across stages of a competition.

3 Further, to our knowledge, the only other sport study to employ the GDGRS (Wrosch et al.,

4 2003), was by Ntoumanis et al. (2014a). It could be argued that more studies are required to

5 validate this scale among athletic populations. Although we examined the factor structure of

6 each scale, the sample size was not sufficient to permit a full SEM, which incorporated

7 measurement error. Consequently, a limitation of the study is that latent variables were not

8 directly examined in the main analyses. Another limitation of this study is that we did not

9 assess the perceived importance of the competition, stress levels during the competition,

10 number or hours spent training, nor the outcome of the competition. These are all variables that could potentially influence all of the constructs we assessed. Indeed, future research could examine these variables in relation to the constructs we examined, as these may impact upon our model.

In summary, we found support for our model that was inspired by theories of selfregulation (i.e., Carver \& Scheier, 1981, 1998; Emmons, 1986; Heckhausen et al., 2010). Based on our findings, we suggest that applied practitioners continue encouraging athletes to set challenging goals, but carefully monitor such goals and help athletes recognize the difference between a goal that requires effort and an unattainable goal. If goals become unattainable, applied consultants could encourage athletes to develop alternative approaches to achieve the same goal, set smaller goals that would ultimately lead to success in their overall personal goal, or develop a completely new goal (Carver \& Scheier, 2005), rather than persisting or simply disengaging from their goal. This is likely to foster challenge appraisals, task-oriented coping, and enhanced well-being. It appears that coping and appraisals are mechanisms that link goal adjustment capacities and well-being, although future scholarly activity could identify other psychological constructs that underpin the goal 
1 adjustment capacities and well-being relationship, with a view to developing theory and 2 creating well-being interventions.

3

4 
1 References

2 Asparouhov, T. \& Muthén, B. (2009). Exploratory structural equation modeling. Structural Equation Modeling, 16, 397-438. doi: 10.1080/10705510903008204

Bentler, P. M., \& Chou, C. P. (1987). Practical issues in structural modeling. Sociological Methods \& Research, 16, 78-117. doi:10.1177/0049124187016001004

Blascovich, J. (2008). Challenge and threat. In A. J. Elliot (Ed.), Handbook of approach and avoidance motivation (pp.431-445). New York: Psychology Press.

Carver, C. S., \& Scheier, M. F. (1981). Attention and self-regulation: A control-theory approach to human behavior. New York, NY: Springer-Verlag.

Carver, C. S., \& Scheier, M. F. (1990). Origins and functions of positive and negative affect: A control-process view. Psychological Review, 97, 19-35. 10.1037/0033-295X.97.1.19.

Carver, C. S., \& Scheier, M. F. (1998). On the self-regulation of behavior. New York, NY: Cambridge University Press.

Carver, C. S., \& Scheier, M. F. (2005). Engagement, disengagement, coping and catastrophe. In A. J. Elliot \& C. S. Dweck (Eds.), Handbook of competence and motivation (pp. 527547). New York, NY: The Guilford Press.

DeFreese, J. D., (2014). Athlete social support, negative social interactions, and psychological health across a competitive sport season. Journal of Sport \& Exercise Psychology, 36, 619-630. doi: 10.1123/jsep.2014-0040

Doron, J., \& Gaudreau, P. (2014). A point-by-point analysis of performance in a fencing match: Psychological processes associated with winning and losing streaks. Journal of Sport \& Exercise Psychology, 36, 3-13. PubMed doi:10.1123/jsep.2013-0043

Dunn, T. J., Baguley, T., \& Brunsden, V. (2013). From alpha to omega: A practical solution to the pervasive problem of internal consistency estimation. British Journal of Psychology, 105, 399-412. doi: 10.1111/bjop.12046 
1 Emmons, R. A. (1986). Personal strivings: An approach to personality and subjective wellbeing. Journal of Personality and Social Psychology, 51,1058-1068. doi:10.1037/00223514.51.5.1058

Folkman, S., \& Moskowitz, J. T. (2000). Positive affect and the other side of coping. American Psychologist, 55, 647-654. doi:10.1037/0003-066X.55.6.647

Gaudreau, P., \& Blondin, J-P. (2002). Development of a questionnaire for the assessment of coping strategies employed by athletes in competitive sport settings. Psychology of Sport and Exercise, 3, 1-34. doi:10.1016/S1469-0292(01)00017-6

Gaudreau, P., \& Blondin, J.-P. (2004). Different athletes cope differently during sport competition: a cluster analysis of coping. Personality and Individual Differences, 36, 1865-1877. http://dx.doi.org/10.1016/j.paid.2003.08.017.

Gaudreau, P., Nicholls, A.R., \& Levy, A.R. (2010). The ups and downs of sports performance: An episodic process analysis of within-person associations. Journal of Sport \& Exercise Psychology, 32, 298-311 Retrieved from http://journals.humankinetics.com/jsep. PubMed

Healy, L. C., Ntoumanis, N., Veldhuijzen van Zanten, J. J. C. S., \& Paine, N. (2014). Goal striving and well-being in sport: The role of contextual and personal motivation. Journal of Sport \& Exercise Psychology, 36, 436-449. http://dx.doi.org/10.1123/jsep.2013-0261

Heckhausen, J., Wrosch, C., \& Schulz, R. (2010). A motivational theory of life-span development. Psychological Review, 117, 32-60. doi:10.1037/a0017668

Kelley, K., \& Lai, K., (2012). MBESS: MBESS. R package version 3.3.2. Retrieved from http://CRAN.R-project.org/package=MBESS

Lazarus, R.S. (1999). Stress and emotion: A new synthesis. New York: Springer.

Lazarus, R. S., \& Folkman, S. (1984). Stress, appraisal and coping. New York: Springer. 
1 Marsh, H. W., Hau K.-T, \& Wen, Z. (2004). In search of golden rules: Comment on hypothesis testing approaches to setting cutoff values for fit indexes and dangers in overgeneralising Hu \& Bentler’s (1999) findings. Structural Equation Modeling, 11, 320-341. doi: 10.1207/s15328007sem1103_2

Muthén, L. K., \& Muthén, B. O. (2012). Mplus user’s guide. Seventh edition. Los Angeles, CA: Muthén \& Muthén.

Nesse, R. M. (2000). Is depression an adaptation? Archives of General Psychiatry, 57, 14-20. doi:10.1001/jamapsychiatry.2015.2107.

Nicholls, A. R., Levy, A. R., \& Perry, J. L. (2015). Emotional maturity, dispositional coping, and coping effectiveness among adolescent athletes. Psychology of Sport and Exercise, 17, 32-39. doi: 10.1016/j.psychsport.2014.11.004

Nicholls, A. R., Polman, R.C.J., \& Levy, A.R. (2012). A path analysis of stress appraisals, emotions, coping, and performance satisfaction among athletes. Psychology of Sport and Exercise, 13, 263-270. doi:10.1016/j.psychsport.2011.12.003

Nicholls, A. R., Perry, J. L., \& Calmeiro, L. (2014). Precompetitive achievement goals, stress appraisals, emotions, and coping among athletes. Journal of Sport \& Exercise Psychology, 36, 433-445. doi: 10.1123/jsep.2013-0266

Nicholls, A. R., Perry, J. L., Jones, L., Morley, D., \& Carson, F. (2013). Dispositional coping, coping effectiveness, and cognitive social maturity among adolescent athletes. Journal of Sport \& Exercise Psychology, 35, 229-238 Retrieved from http://journals.humankinetics.com/jsep. PubMed

Ntoumanis, N., Healy, L. C., Sedikides, C., Duda, J., Stewart, B., Smith, A., \& Bond, J. (2014). When the going gets tough: The "why” of goal striving matters. Journal of Personality, 82, 225-236. doi: 10.1111/jopy.12047 
1 Ntoumanis, N., Healy, L. C., Sedikides, C., Smith, A. L., \& Duda, J. L. (2014). Selfregulatory responses to unattainable goals: The role of goal motives. Self and Identity, 13, 594-612. http://dx.doi.org/10.1080/15298868.2014.889033

Peacock, E. J., \& Wong, P. T. P. (1990). The stress appraisal measure (SAM): A multidimensional approach to cognitive appraisal. Stress Medicine, 6, 227-236. doi:10.1002/smi.2460060308

Pérez-García, A. M., Oliván, S., \& Bover, R. (2014). Subjective well-being in heart failure patients: Influence of coping and depressive symptoms. International Journal of Behavioral Medicine, 21, 258-265. doi: 10.1007/s12529-013-9311-4

Perry, J. L., Nicholls, A. R., Clough, P. J., \& Crust, L. (2015). Assessing model fit: Caveats and recommendations for confirmatory factor analysis and exploratory structural equation modeling. Measurement in Physical Education and Exercise Science, 19, 12-21. doi: 10.1080/1091367X.2014.952370

R Development Core Team (2012). R: A language and environment for statistical computing. Vienna, Austria. Retrieved from http://www.R-project.org/

Ryan, R. M., \& Deci, E. L. (2001). On happiness and human potential: A review of research on hedonic and eudaimonic well-being. Annual Review of Psychology, 52,141-166. http://dx.doi.org/10.1146/annurev.psych.52.1.141

Schellenberg, B. J. I., Gaudreau, P., \& Crocker, P. R. E. (2013). Passion and coping: Relationships with changes in burnout and goal attainment in collegiate volleyball players. Journal of Sport \& Exercise Psychology, 35, 270-280 Retrieved from http://journals.humankinetics.com/jsep. PubMed

Schmid, K., \& Muldoon, O. T. (2015). Perceived threat, social identification, and psychological well-being: The effects of political conflict exposure. Political Psychology, 36, 75-92. http://dx.doi.org/10.1111/pops.12073 
1 Shimazu, A., \& Schaufeli, W. B. (2007). Does distraction facilitate problem-focused coping with job stress? A 1 year longitudinal study. Journal of Behavioral Medicine, 30, 423434. doi: 10.1007/s10865-007-9109-4

Smith, A. L., \& Ntoumanis, N. (2014). An examination of goal motives and athletes' selfregulatory responses to unattainable goals. International Journal of Sport Psychology, 45, 538-558. doi: 10.7352/IJSP2014.45.538

Smith, A. L., Ntoumanis, N., Duda, J. L., \& Vansteenkiste, M. (2011). Goal striving, coping, and well-being: A prospective investigation of the self-concordance model in sport. Journal of Sport \& Exercise Psychology, 33, 124-145. http://journals.humankinetics.com/jsep. PubMed

Smith, R. E., Leffingwell, T. R., \& Ptacek, J. T. (1999). Can people remember how they coped? Factors associated with discordance between same-day and retrospective reports. Journal of Personality and Social Psychology, 76, 1050-1061. http://dx.doi.org/10.1037/0022-3514.76.6.1050

Staufenbiel, K., Lobinger, B., \& Strauss, B. (2015). Home advantage in soccer - A matter of expectations, goal setting, and tactical decisions of coaches? Journal of Sports Sciences, 33, 1932-1941. http://dx.doi.org/10.1080/02640414.2015.1018929

Tennant, R., Hiller, R., Platt, S., Joseph, S., Weich, S., Parkinson, J., . . . Stewart-Brow, S. (2007). The Warwick-Edinburgh Mental Well-being Scale (WEMWBS): Development and UK validation. Health and Quality of Life Outcomes, 63, 1-13. doi: doi:10.1186/1477-7525-5-63

Tomaka, J., Blascovich, J., Kibler, J., \& Ernst, J. M. (1997). Cognitive and physiological antecedents of threat and challenge appraisal. Journal of Personality and Social Psychology, 73, 63-72. PubMed doi:10.1037/0022-3514.73.1.63 
1 Watson. D., Tellegen, A., \& Clark, L. (1988). Development and validation of brief measures of positive and negative affect: The PANAS scales. Journal of Personality and Social Psychology, 54, 1063-1070. http://dx.doi.org/10.1037/0022-3514.54.6.1063

World Health Organisation, (2004). Promoting Mental Health; Concepts emerging evidence and practice. Summary report Geneva; World Health Organisation. Retrieved from http://www.who.int/mental_health/evidence/MH_Promotion_Book.pdf

Wrosch, C., Amir, E., \& Miller, G. E. (2011). Goal adjustment capacities, coping, and subjective well-being: The sample case of caregiving for a family member with mental illness. Journal of Personality and Social Psychology, 100, 934-946. doi:

$$
10.1037 / \mathrm{a} 0022873
$$

Wrosch, C., \& Miller, G. E. (2009). Depressive symptoms can be useful: Self-regulatory and emotional benefits of dysphoric mood in adolescence. Journal of Personality and Social Psychology, 96, 1181-1190. doi:10.1037/a0015172

Wrosch, C., Miller, G. E., Scheier, M. F., \& Pontet, S. B. (2007). Giving up on unattainable goals: Benefits for health? Personality and Social Psychology Bulletin, 33, 251-265. doi:10.1177/0146167206294905

Wrosch, C., Scheier, M. F., Miller, G. E., Schulz, R., \& Carver, C. S. (2003). Adaptive selfregulation of unattainable goals: Goal disengagement, goal reengagement, and subjective well-being. Personality and Social Psychology Bulletin, 29, 1494-1508. doi:10.1177/0146167203256921 
Table 1. Descriptive statistics, univariate normality estimates, and omega point estimates with confidence intervals

\begin{tabular}{lccccccc}
\hline Variable & Mean & SD & Min & Max & Skew & Kurt & $\omega(95 \%$ CI $)$ \\
\hline Goal disengagement & 3.24 & .99 & 1.00 & 5.00 & -.67 & .05 & $.85(.80, .89)$ \\
Goal re-engagement & 3.42 & .68 & 1.00 & 5.00 & .11 & .50 & $.69(.58, .79)$ \\
Threat & 2.43 & .95 & 1.00 & 5.00 & .43 & -.38 & $.79(.73, .83)$ \\
Challenge & 3.77 & .90 & 1.75 & 5.00 & -.15 & -1.14 & $.77(.70, .81)$ \\
Task coping & 3.02 & .64 & 1.30 & 4.52 & .08 & -.20 & $.84(.75, .88)$ \\
Distraction coping & 3.04 & 1.01 & 1.00 & 4.88 & -.13 & -1.01 & $.89(.87, .91)$ \\
Disengagement coping & 2.43 & .75 & 1.00 & 4.50 & .01 & -.55 & $.70(.60, .76)$ \\
Well-being & 3.65 & .75 & 1.86 & 5.00 & -.04 & -.35 & $.85(.81, .88)$ \\
\hline
\end{tabular}


Table 2. Bivariate correlations between variables

\begin{tabular}{lccccccc}
\hline Variable & 1 & 2 & 3 & 4 & 5 & 6 & 7 \\
\hline 1. Goal disengagement & - & & & & & & \\
2. Goal re-engagement & $.17^{*}$ & - & & & & & \\
3. Threat & .13 & $-.26^{* *}$ & - & & & & \\
4. Challenge & $-.30^{* *}$ & $.36^{* *}$ & $-.33^{* *}$ & - & & & \\
5. Task-oriented coping & -.13 & $.35^{* *}$ & $-.26^{* *}$ & $.66^{* *}$ & - & & \\
6. Distraction-oriented & $.30^{* *}$ & $-.28^{* *}$ & $.48^{* *}$ & $-.59^{* *}$ & $-.33^{* *}$ & - & \\
$\quad \begin{array}{l}\text { coping } \\
\text { 7. Disengagement- }\end{array}$ & .11 & $-.29^{* *}$ & $.43^{* *}$ & $-.34^{* *}$ & $-.21^{* *}$ & $.52^{* *}$ & - \\
$\quad \begin{array}{l}\text { oriented coping } \\
\text { 8. Well-being }\end{array}$ & $-.16^{*}$ & $.25^{* *}$ & $.31^{* *}$ & $.28^{* *}$ & $.40^{* *}$ & -.10 & $.24^{* *}$ \\
\hline
\end{tabular}




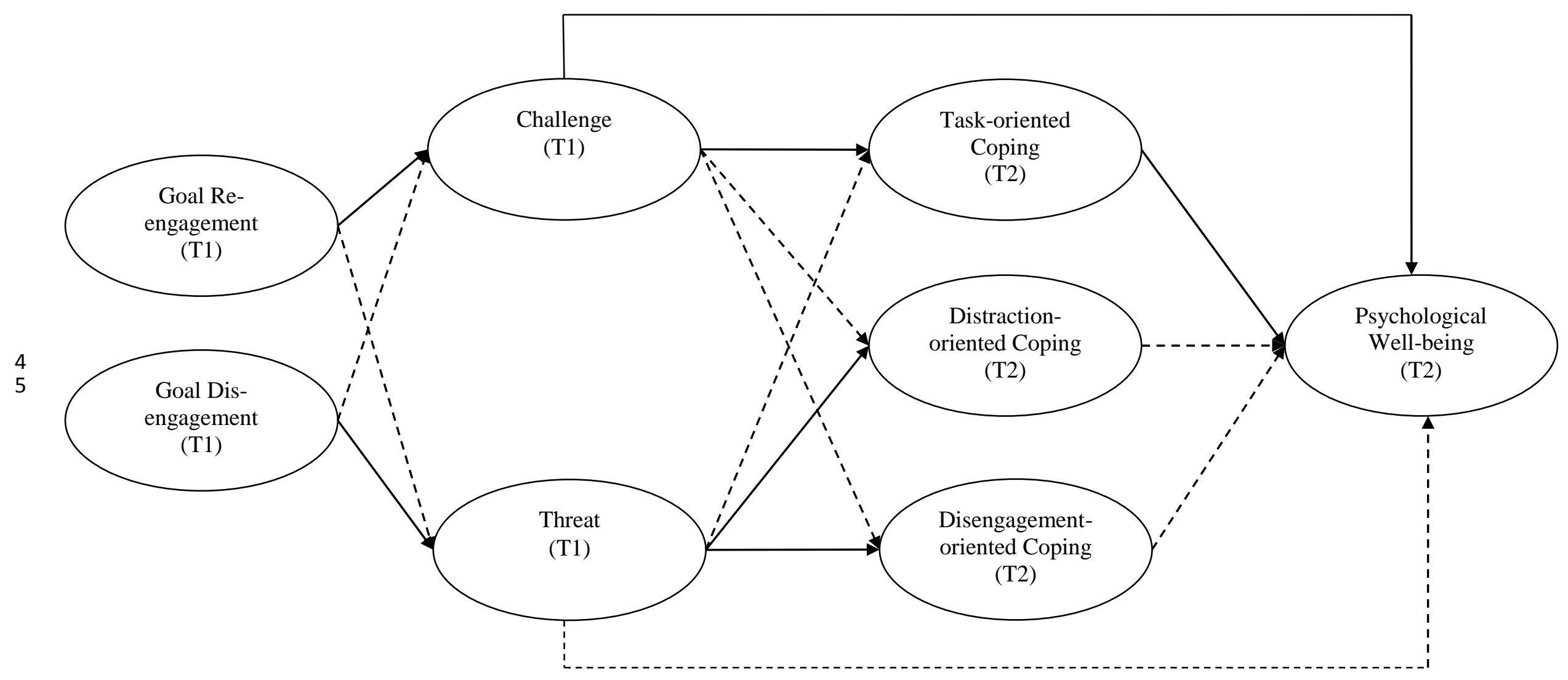


1 Figure 2. Structural Equation Model with Parameter Estimates from Goal Adjustment, Stress Appraisal, Coping, and Psychological Well-being. $2 \quad * p<.05, * * p<.01$.

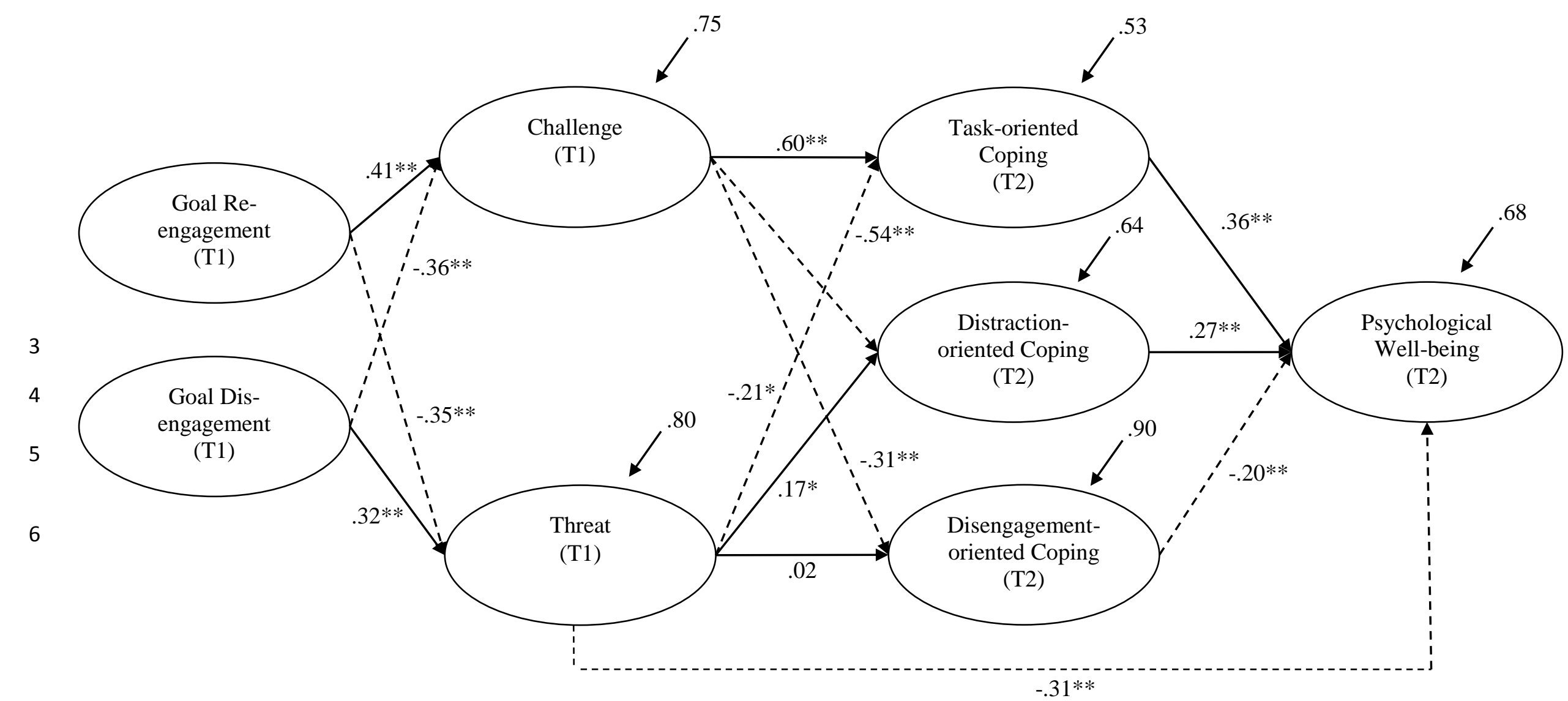

